\title{
An analysis of Tobacco Industry pricing strategies in 23 European Union countries using commercial pricing data
}

Authors:

May CI van Schalkwyk ${ }^{1 *}$, Martin $\mathrm{McKee}^{2}$, Jasper V Been ${ }^{3,4}$, Christopher Millett ${ }^{1}$, Filippos T Filippidis $^{1}$

${ }^{1}$ Public Health Policy Evaluation Unit, School of Public Health, Imperial College London, London, UK

${ }^{2}$ Faculty of Public Health and Policy, London School of Hygiene and Tropical Medicine, London, UK

${ }^{3}$ Department of Paediatrics, division of Neonatology, and Department of Public Health, Erasmus MC - Sophia Children's Hospital, University Medical Centre Rotterdam, Netherlands

${ }^{4}$ Usher Institute of Population Health Sciences and Informatics, The University of Edinburgh, Edinburgh, UK

*Corresponding author: May CI van Schalkwyk

Email: m.van-schalkwyk@imperial.ac.uk

Phone: +44 (0)20 75943368

Department of Primary Care and Public Health, Imperial College London, London W6 6RP, UK

Word count: 3503 


\section{ABSTRACT: \\ Background:}

The Tobacco Industry (TI) can act to undermine the impact of tobacco tax increases by adopting various pricing strategies. Little is known about strategies used across the European Union (EU), except for the UK.

\section{Aims:}

To examine pricing strategies adopted by the TI in the EU, and whether they differ by cigarette price segment, or between manufactured and roll-your-own (RYO) cigarettes.

\section{Methods:}

A longitudinal analysis of commercial pricing data for manufactured and RYO cigarettes from 23 EU countries, 2006-2017. Price and revenue trends were explored. Linear regression estimated the average annual change in revenue and linear fixed-effects panel regression models were used to explore the association between changes in median revenue (net of tax and adjusted for inflation) and tax increases in different price segments of manufactured cigarettes.

\section{Results:}

Over the 11-year period price gaps were observed in all countries. Average annual adjusted median net revenue per pack increased in 19 of 23 countries for manufactured and RYO cigarettes. A tax increase was associated with a significant decrease of $-€ 0.09$ in adjusted median net revenue per pack $(95 \%$ Confidence Interval $[\mathrm{CI}]-0.16$ to -0.03$)$ in the cheap cigarette price segment, while no change was detected in the expensive cigarette price segment (-€0.05, 95\% CI -0.11 to 0.01$)$.

\section{Conclusion:}


Across the EU, pricing strategies adopted by the TI maintained or increased price gaps and retained cheaper tobacco products in the market, diminishing the impacts of tobacco tax increases. Further strengthening of tobacco taxation policy is needed to maximise the public health impacts. 


\section{INTRODUCTION}

Increasing the price of tobacco products by means of tax rises is among the most effective population-level tobacco control measures, ${ }^{1-3}$ and a cornerstone of the World Health Organization (WHO) Framework Convention on Tobacco Control. ${ }^{4}$ The Tobacco Industry (TI) has long sought ways to influence tax policies and to undermine the effects of tax increases. ${ }^{5-}$ ${ }^{8}$ The European Union (EU), in Directive 2011/64/EU, has legislated on tobacco taxation, but only to stipulate the minimum level of excise duty that countries must impose. ${ }^{8}$ This Directive is currently being reviewed so it is important to understand how the TI has responded to its existing provisions.

The TI can employ a range of measures to minimise the effects of tax rises on tobacco consumption. It can absorb the tax, thereby lowering its revenue (undershifting), pass it on in full through price increases commensurate to the tax increase, or overshift the tax, that is, raise prices above and beyond the tax increase thereby increasing revenue. It can take advantage of differing price elasticities of cheap and expensive products ${ }^{9}$; it can segment the market, thereby maintaining sales of cheap tobacco to price-sensitive consumers while increasing profits on more expensive products. ${ }^{5,6}$ There is evidence that the TI does employ these and other pricing strategies in several countries, with the most comprehensive studies conducted in the UK. ${ }^{5,6,10-}$ ${ }^{13}$ Such strategies undermine the public health objectives of tobacco tax increases as more smokers, particularly the poorest, ${ }^{14,15}$ are now consuming cheaper forms of manufactured or roll-your-own (RYO) cigarettes to maintain consumption. ${ }^{14-17}$ This is problematic as access to cheap tobacco appears to reduce motivation for, and success in, quitting smoking. ${ }^{18-21}$ Evidence from Ireland demonstrates that while the industry may warn governments against raising taxes, citing multiple potential adverse outcomes secondary to price increases, companies consistently increase the prices they charge for some products to maximise profit. ${ }^{22}$ 
However, there is no comprehensive picture of the strategies employed by the TI across the EU, which could inform the review of the Directive. The prospect of new legislation provides an obvious window of opportunity to advance tobacco control..$^{23,24}$ We have therefore undertaken a longitudinal analysis of EU country-specific pricing data on commercial cigarette and RYO tobacco products to ascertain changes over time in the context of tax increases, seeking evidence of tax undershifting or overshifting, and whether this varies across price segments and products. 


\section{METHODS}

We conducted a longitudinal analysis of TI pricing strategies using routinely collected commercial pricing and taxation data on both cigarette and RYO tobacco products sampled from 23 EU countries from 2006 to 2017. Ethical approval was therefore not required.

\section{Data sources}

Euromonitor Passport

Euromonitor International is a market research company that publishes annual, countryspecific reports on tobacco markets. ${ }^{25}$ These include product pack size, brand and company, and prices in local currency. Sampling is designed to capture products that dominate the local market. Pricing data were available for cigarettes and RYO tobacco from 23 EU countries for years 2006-2017 (excluding Austria, Croatia, Cyprus, Luxembourg and Malta). Data were missing for 2007 from Belgium and 2006 from Slovakia. The initial dataset contained over 40,000 tobacco product pricing observations.

\section{European Commission}

Tobacco excise duties for manufactured cigarettes and RYO tobacco were obtained for all 23 EU countries and years included in the analysis from the European Commission's Communication and Information Resource Centre for Administrators, Businesses and Citizens $(\mathrm{CIRCABC}){ }^{26}$

\section{Data}

Price standardisation and adjustment

For comparison, prices were standardised to a 20-stick pack price for all cigarette and RYO tobacco products (referred to as manufactured and RYO cigarettes from here on) ${ }^{5,6,27}$ For RYO 
cigarettes, one stick was assumed to contain $0.75 \mathrm{~g}$ of tobacco, based on recent European data. ${ }^{5,28,29}$ Local currencies were converted into Euros using the historical exchange rates on the $1^{\text {st }}$ of the month during which the data had been collected by Euromonitor, using data obtained from XE Corporation. ${ }^{30}$ Pack prices were adjusted for inflation using the Harmonised Index of Consumer Prices (HICP), compiled by Eurostat, ${ }^{31,32}$ and displayed in real terms using 2015 as the reference year.

Annual samples of $<5$ product price observations were removed. Thus, a total of 100 manufactured $(0.3 \%)$ and $138 \mathrm{RYO}(2.0 \%)$ cigarette pricing observations were excluded from the analysis including all Romanian RYO data.

Price segmentation

Four approaches to divide products into cheap and expensive were identified in the literature: (1) extensive review of commercial literature, ${ }^{5,6,33}$ (2) division using quantiles, ${ }^{34,35}$ (3) using prices of market-dominant brands, ${ }^{11-13}$ or (4) a data-driven approach based on visual inspection of the price distribution. ${ }^{36}$ Given the number of countries and years (274 country-year samples), the feasibility of the quantile and data driven methods were assessed.

We observed that pricing distributions, both within and between countries over time, assume many different shapes, precluding the visual data-driven approach. A quantile-based approach was therefore adopted to segment the data. Standardised 20 -stick pack prices per year and country (in Euros) were arranged in ascending order and divided into quartiles. Products within the lower and upper quartiles (lower and upper $25^{\text {th }}$ percentiles) were designated as cheap and expensive products, respectively. Segmentation of RYO cigarette pricing data was not undertaken as annual sample sizes were small. 


\section{Trends in manufactured and RYO cigarette pack prices}

The median 20-stick pack price of cheap, expensive and RYO cigarettes, adjusted for inflation, was calculated by year and country and analysed graphically. The median was used as the measure of price given the skewed nature of pricing data. ${ }^{37}$ Countries were divided into EU members prior to 2004 and those that joined afterwards. ${ }^{38}$

\section{Tax pass through}

Tobacco tax pass through, the extent to which companies shifted tobacco tax increases onto consumers through price increases or absorbed them by reducing profits, was assessed by calculating changes in median net revenue per pack of cheap, expensive and RYO cigarettes. ${ }^{5,6}$ The median net revenue was calculated by subtracting the total tax paid per pack (specific, ad valorem and VAT), based on reported duties, ${ }^{26}$ from the median pack price (Supplementary methods). Median net revenue was adjusted for inflation and presented graphically by year and product for each country. Year-to-year changes in adjusted median net revenue were then calculated by segment and product for all countries for the period 2006-2017.,6 If taxes are passed on fully to the consumer, the median net revenue should remain unchanged. A decrease in net revenue (negative change) suggests that the tax was (partially) absorbed by the company while an increase (positive change) implies overshifting of taxes, that is, the industry increased the price in excess of the tax increase. ${ }^{6}$

\section{Statistical analysis}

For each country, we used separate linear regression models to estimate average annual change in adjusted median net revenue for expensive, cheap or RYO cigarettes by regressing adjusted median net revenue on time. 
A fixed-effects panel regression model was used separately for cheap and expensive cigarettes to explore the association between changes in adjusted median net revenue per 20-stick pack of manufactured cigarettes and tax increases. Panel regression models are an established method to analyse routinely collected data from multiple units over time, controlling for the clustering of observations within each country. ${ }^{27,39}$ The fixed-effects specification allowed us to control for unobserved time-invariant factors that may be associated with the independent variables at the level of the country, and was supported by the results of the Hausman specification test. The model estimated the association between the independent (tax increase) and outcome (net revenue per pack) variable within each country but not between-country associations. Tax increase was included as a binary variable classified as present if there was an increase of $\geq 0.5 \%$ in the reported total tax burden compared with the previous year. Tax burden is expressed as a percentage of the tax included retail selling price (TIRSP, 2006-2010) or weighted average price (WAP, 2011-2017). ${ }^{26}$ This threshold was adopted to exclude small increases in the recorded total tax burden potentially induced by non-tax changes, e.g. fluctuations in exchange rates. A sensitivity analysis with alternative thresholds of $1 \%, 2 \%$ and $3 \%$, was also undertaken. Changes in net revenue one year post a tax increase were estimated by including a 1-year time lag variable. This analysis was not undertaken for RYO cigarettes as: (1) small sample sizes precluded segmentation and (2) total tax burden as a percent of the TIRSP/WAP is not reported for RYO tobacco. Data were analysed using Microsoft Excel and Stata/IC15.1. ${ }^{40}$ The full regression models are available in the supplementary material. 


\section{RESULTS}

\section{Price segmentation}

Pricing data were available for 34,107 manufactured cigarette and 6,963 RYO tobacco products from 23 EU countries in the period 2006-2017 (Supplementary Tables 1\&2). All pricing distributions were separated into unique quartiles, except for data collected in 2008 for Denmark and 2016 for Romania as there was no price differentiation above the lowest quartile.

\section{Analysis of pricing}

Trends in adjusted median price of expensive and cheap cigarettes and RYO cigarettes are shown in Figures $1 \mathrm{~A} \& \mathrm{~B}$. The adjusted median price of a 20-pack of expensive cigarettes ranged from $€ 1.64$ (Romania) to $€ 13.46$ (UK) in 2006 and from $€ 3.07$ (Bulgaria) to $€ 12.89$ (Ireland) in 2017. The adjusted median price of a 20-pack equivalent of RYO cigarettes ranged from $€ 0.79$ (Hungary) to $€ 5.03$ (UK) in 2006 and from $€ 1.57$ (Hungary) to $€ 7.99$ (Ireland) in 2017. The largest median difference, $€ 4.56$ (range $€ 2.91$ to $€ 8.42$ ), was observed in the UK, between expensive and RYO segments, and the lowest was observed in Bulgaria, between cheap manufactured and RYO cigarettes, $€ 0.01$ (range $-€ 0.29$ to $€ 0.43$ ).

Tobacco products were consistently cheaper in the post-2004 than pre-2004 countries, typically costing below $€ 4.00$ per pack. Prices increased gradually in most countries over the study period. This was also true when trends were measured using local currency (Supplementary Material).. 


\section{Tax pass through}

Tax policy

During the period of analysis, all countries changed tobacco taxation for both manufactured cigarette and RYO tobacco (Supplementary Figures 3-5). In most, there were both increases in, and adjustments to, tax components, although their scale and nature varied.

Analysis of changes in net revenue

In all countries, and in all years, the adjusted median net revenue for a 20 -pack of expensive manufactured cigarettes remained above that for cheap and RYO cigarettes in all pre-2004 countries (Figure 2A\&B). The adjusted median net revenue was higher for cheap manufactured cigarettes compared to RYO cigarettes in 9 of the 13 pre-2004 countries throughout the study period. In 5 of the 9 post-2004 countries for which RYO data were included, the adjusted median net revenue was greater than that for cheap manufactured cigarettes in most years. In Bulgaria, Latvia and Lithuania the adjusted median net revenue obtained from a 20 -stick pack of RYO cigarettes was greater than that for expensive manufactured cigarettes in most years, the difference ranging from $-€ 0.09$ to $€ 0.44$, $-€ 0.18$ to $€ 0.40$ and $-€ 0.04$ to $€ 0.37$ respectively. As noted above, tax-shifting was assessed by calculating the year-on-year changes in adjusted median net revenue (Supplementary Tables 3\&4). Evidence of overshifting (positive change) and/or undershifting (negative change) could be seen in all countries.

The average annual change in median net revenue for manufactured and RYO cigarettes was positive in the majority of countries over the period 2006-2017 (Table 1). There were positive changes for expensive and RYO cigarettes in 9 of 10 pre-2004 countries and in 3 of 5 for cheap cigarettes, while changes were all positive in post-2004 countries. In the post-2004 countries, significant annual increases in median net revenue were more common with cheap 
manufactured cigarettes than with expensive manufactured and RYO cigarettes. In contrast, in pre-2004 countries, statistically significant increases were more common with expensive manufactured cigarettes.

We then used linear fixed-effects panel regression analysis to ascertain the consequences of a tax increase $(\geq 0.5 \%)$ on adjusted median net revenue of cigarettes. There was a significant reduction of - $€ 0.09$ in revenue per pack from cheap manufactured cigarettes (95\% Confidence Interval $[\mathrm{CI}]-0.16$ to -0.03 ) in years when tax increases were observed (Table 2). There was no statistically significant change with expensive cigarettes (-€0.05, 95\% CI -0.11 to 0.01$)$. A sensitivity analysis using different thresholds, $1 \%, 2 \%$ or $3 \%$, produced consistent findings (Supplementary Table 5). While a reduction in adjusted median net revenue was observed in the year following a tax increase, this decrease was not statistically significant using a threshold of $0.5 \%$. However, a significant reduction in adjusted median net revenue for the cheap segment 1-year post tax increase was observed when using thresholds of $1 \%, 2 \%$ and $3 \%$. No significant association between adjusted median net revenue and tax increase was observed for the expensive segment. 
Table 1: Linear regression analysis of the estimated annual change in adjusted median net revenue for manufactured and RYO cigarettes over the period 2006 to 2017 in all countries grouped by year of EU accession.

Country $\quad$ Estimated average annual change in adjusted median net revenue, $€$

\begin{tabular}{|c|c|c|c|}
\hline Pre-2004 & Expensive: ß (95 \% CI) & Cheap: B (95 \% CI) & RYO: B (95 \% CI) \\
\hline Belgium $^{\dagger}$ & $0.035 *(0.018$ to 0.053$)$ & $0.015(-0.002$ to 0.033$)$ & $0.015 *(0.002$ to 0.029$)$ \\
\hline Denmark & $0.023(-0.057$ to 0.103$)$ & $-0.033(-0.111$ to 0.044$)$ & $0.023 *(0.003$ to 0.044$)$ \\
\hline Finland ${ }^{\dagger}$ & $-0.014 *(-0.027$ to -0.001$)$ & $-0.001(-0.01$ to 0.008$)$ & $-0.016^{*}(-0.026$ to -0.005$)$ \\
\hline France $^{\dagger}$ & $0.038 *(0.015$ to 0.06$)$ & $0.042 *(0.021$ to 0.063$)$ & $0.064 *(0.038$ to 0.09$)$ \\
\hline Germany & $0.049 *(0.029$ to 0.07$)$ & $0.064 *(0.048$ to 0.079$)$ & $0.034 *(0.008$ to 0.059$)$ \\
\hline Greece & $0.026(-0.016$ to 0.067$)$ & $-0.001(-0.022$ to 0.02$)$ & $-0.002(-0.019$ to 0.014$)$ \\
\hline Ireland & $0.145^{*}(0.101$ to 0.189$)$ & $0.038(0$ to 0.077$)$ & $0.08 *(0.039$ to 0.121$)$ \\
\hline Italy & $0.017 *(0.014$ to 0.02$)$ & $0.005(-0.003$ to 0.013$)$ & $0.024 *(0.019$ to 0.029$)$ \\
\hline Netherlands & $0.081 *(0.044$ to 0.119$)$ & $0.044(-0.008$ to 0.096$)$ & $0.030 *(0.001$ to 0.058$)$ \\
\hline Portugal & $0.072 *(0.053$ to 0.091$)$ & $0.051 *(0.03$ to 0.072$)$ & $0.039(-0.015$ to 0.092$)$ \\
\hline Spain $^{\dagger}$ & $0.044 *(0.031$ to 0.057$)$ & $0.043 *(0.03$ to 0.056$)$ & $0.042 *(0.014$ to 0.07$)$ \\
\hline Sweden & $0.053 *(0.013$ to 0.092$)$ & $-0.056 *(-0.097$ to -0.015$)$ & $0.094(-0.011$ to 0.2$)$ \\
\hline United Kingdom & $0.098(-0.104$ to 0.3$)$ & $0.084(-0.028$ to 0.196$)$ & $0.121 *(0.056$ to 0.187$)$ \\
\hline
\end{tabular}

\section{Post-2004}

\begin{tabular}{|c|c|c|c|}
\hline Bulgaria $^{\dagger}$ & $0.024(-0.016$ to 0.063$)$ & $0.014(-0.022$ to 0.05$)$ & $0.023 *(0.003$ to 0.044$)$ \\
\hline Czech Republic & 0.005 (-0.018 to 0.028$)$ & $0.04 *(0.029$ to 0.051$)$ & $-0.028(-0.057$ to 0.001$)$ \\
\hline Estonia & $0.022(-0.02$ to 0.064$)$ & $0.022(-0.005$ to 0.048$)$ & $0.012(-0.024$ to 0.049$)$ \\
\hline Hungary & $0.005(-0.022$ to 0.032$)$ & $0.043^{*}(0.016$ to 0.071$)$ & $0.016 *(0.005$ to 0.026$)$ \\
\hline Latvia $^{\dagger}$ & $0.023^{*}(0.003$ to 0.042$)$ & $0.043^{*}(0.027$ to 0.060$)$ & $0.035(-0.005$ to 0.075$)$ \\
\hline Lithuania $^{\dagger}$ & $0.002(-0.031$ to 0.035$)$ & $0.036^{*}(0.015$ to 0.058$)$ & $0.048 *(0.027$ to 0.069$)$ \\
\hline Poland & $0.037 *(0.016$ to 0.057$)$ & $0.039 *(0.023$ to 0.056$)$ & $0.016(-0.009$ to 0.04$)$ \\
\hline Romania $^{\S}$ & $0.102 *(0.045$ to 0.159$)$ & $0.083 *(0.046$ to 0.12$)$ & - \\
\hline Slovakia $^{\dagger}$ & $0.007(-0.017$ to 0.031$)$ & $0.035^{*}(0.007$ to 0.062$)$ & $0.107 *(0.068$ to 0.146$)$ \\
\hline Slovenia & $0.029 *(0.023$ to 0.035$)$ & $0.012 *(0.004$ to 0.019$)$ & $-0.008(-0.022$ to 0.006$)$ \\
\hline
\end{tabular}

$\dagger$ Less than 12 annual data points available for the analysis

* Statistically significant

${ }^{\S}$ RYO data not used due to small $(<5)$ annual sample sizes 
Table 2: Association between tax increase and change in adjusted median net revenue $(€)$ estimated using linear fixed-effects panel regression models.

\begin{tabular}{ccccc}
\hline Price segment & Tax increase & $\boldsymbol{\beta}$ & P value & 95 \% CI \\
\hline \multirow{2}{*}{ Cheap } & Within year & -0.09 & 0.003 & -0.16 to -0.03 \\
& 1-year lag & -0.05 & 0.106 & -0.11 to 0.01 \\
\multirow{2}{*}{ Expensive } & Within year & -0.05 & 0.106 & -0.11 to 0.01 \\
& 1-year lag & -0.01 & 0.823 & -0.09 to 0.07 \\
\hline
\end{tabular}

Note: Regression analyses were performed separately for each cigarette price segment. Pricing data were not available for every year in all countries (see methods for details). 


\section{DISCUSSION}

Our findings suggest that across 23 EU countries, between 2006 and 2017, tax increases were selectively undershifted in the cheap segment of the cigarette market and there was exploitation of the low tax rate imposed on RYO tobacco. This likely maintained availability of cheap forms of tobacco while realising increases in revenue.

Throughout the study period, a range of prices was observed, with comparatively cheaper tobacco products being present in all markets in the form of cheaper manufactured and/or RYO cigarettes. Although tax increases were imposed on RYO tobacco, the price of RYO cigarettes was consistently below that of expensive cigarettes in all 23 countries, with a price gap between expensive and cheap cigarettes also seen in most years. This suggests that smokers had the opportunity to downtrade to a cheaper form of tobacco in the face of tax increases, as observed in previous UK studies, ${ }^{5,6}$ thereby negating the potential impact on consumption. This is in agreement with studies in the EU, and elsewhere, demonstrating ongoing availability, and increasing use of, relatively cheap forms of tobacco, factors known to undermine cessation efforts. ${ }^{16,20,21,41}$ In this way, cheap and RYO cigarettes serve as substitutes for more expensive products, ${ }^{42-45}$ a phenomenon supported by the large price gap between manufactured and RYO cigarettes across many countries,${ }^{31}$ and the country-level analyses presented here.

In the majority of countries, the annual average change in adjusted net revenue for a pack of expensive, cheap and RYO cigarettes was estimated to be positive, demonstrating that while overall consumption of cigarettes, particularly premium brands, is declining, differential shifting of taxes and rising consumption of cheaper forms of tobacco, such as RYO, increase industry revenue and presumably profits. ${ }^{5,6}$ Interestingly, among post-2004 countries the number of significant increases in revenue was greatest in the cheap cigarette segment, while 
this was observed in the expensive cigarette price segment among pre-2004 countries. This may reflect how Trans-national Tobacco Companies (TTCs) lobby for policies that favour the sale of international premium brands in Eastern European countries, but promote cheaper products through static prices and price promotions in countries with high tobacco taxes and strict tobacco control, such as the UK. ${ }^{5-7,46,47}$ In addition, the observed net revenue obtained from RYO cigarettes was, in some countries, greater than with manufactured cigarettes, both cheap and, in some cases, expensive. This may reflect exploitation by the industry of the differential taxation systems imposed on manufactured versus RYO cigarettes, as has been reported recently in the UK and Spain. ${ }^{8,29,48}$

The regression analysis provided an overview of the patterns of change. Following tax increases, revenue from cheap cigarettes fell but there was no change with expensive cigarettes. Put another way, the TI absorbed tax increases on cheaper cigarettes, to ensure that they remained affordable, but passed tax increases on to expensive cigarettes. Two previous studies revealed varying patterns of tax-shifting across Europe ${ }^{38,49}$ but both looked at the overall cigarette market, rather than price segments within it, using the most popular price category (a measure subsequently shown to reflect premium product prices ${ }^{6,48}$ ) and one was performed before enlargement of the EU and market consolidation. ${ }^{49}$ A Ukraine-based study suggested that, when analysing the cigarette market as a whole, lower tax increases were absorbed but larger ones were overshifted. ${ }^{50}$ Our findings suggest that undershifting of taxes was observed in the cheap segment of the manufactured cigarette market, regardless of the magnitude of tax increase included in the model. By analysing differential use of tax-shifting among price segments, this study adds to evidence from previous studies and, in combination with UKbased analyses, ${ }^{5,6}$ establishes the importance of studying the impacts of taxes by price segment and product. 
To our knowledge, this is the first study using a fixed-effects panel regression model with data from multiple time points and countries to measure the association between tax and revenue changes across the EU, while controlling for the clustering of the within-country observations as well as regional and unobserved time-invariant factors, potentially associated with tax changes. As TI responses to tax increases could plausibly vary with the timing of a tax increase relative to previous increases, or in anticipation of future taxes, time may explain, in part, any association between tax and revenue changes. Consequently, we did not include time in our model. It is possible that our findings could differ if we had looked only at individual countries but this would have reduced statistical power. However, as four TTCs dominate the EU market,${ }^{51}$ it is reasonable to estimate strength of association across the region as a whole.

This study has several limitations. The nature of our data precluded analysis using industrydefined price segments, i.e., use of ultra-low, discount, mid-range and premium, limiting comparability with other studies. ${ }^{5,6}$ However, our data source has the advantage of size, permitting analysis of trends in price and revenue of manufactured and RYO cigarettes at country level over an 11-year period. Our use of quartiles can be justified as being data driven. Second, Euromonitor International data are intended predominantly for commercial use and do not include some parameters such as price promotions that may reduce price. However, given how price promotions tend to be concentrated in the cheap segment of the market, ${ }^{5}$ their omission is likely to have underestimated the price differentials we found. Standardisation of pack sizes may similarly have led to an underestimate of the real-world price gap between cheap and expensive pack prices. ${ }^{5}$ On the other hand, as the data reflect retail prices they are not influenced by recall or rounding biases introduced by self-reporting of prices. ${ }^{52,53}$ Importantly, prior studies support the use of commercial data in public health research. ${ }^{27,54,55}$ 
Additionally, the data are collected annually, so we could not analyse changes on a month-bymonth scale. Studies in the UK and South Africa revealed undershifting immediately after tax increases with subsequent recovery and an increase in revenue through overshifting later in the year. ${ }^{5,10}$ We could also not segment the RYO price distributions, limiting the analysis of differential tax-shifting to manufactured cigarettes. We also assumed an average weight of $0.75 \mathrm{~g}$ for RYO cigarettes, although variation has been documented in reported weights between EU countries. ${ }^{28}$ Finally, we could not assess changes in market share or shifts in individual choice of brands, and nor could we take account of illicit tobacco products, although this comprises a small share of the EU market, contrary to what might be assumed given the strenuous efforts by the TI to exaggerate it as part of their argument against tax rises. ${ }^{8,16,56}$ Similarly, we could not assess affordability, so price increases might not reduce affordability. ${ }^{38}$ These limitations are, however, unlikely to explain fully the key findings of our analysis.

\section{Research and Policy implications}

Further research is needed, in particular of pricing strategies adopted at national or regional level, incorporating data on price promotions and measures of consumption and affordability. Other research could explore pricing strategies adopted in response to changes in the various elements of tobacco tax to assess whether these vary by price segment and tobacco product.

Complementing previous UK-based analyses, the evidence presented here points to TI pricing strategies that potentially undermined the public health objectives of tobacco taxes. As EU Directive 2011/64/EU is currently under review, ${ }^{31}$ there is a window of opportunity to address this issue. ${ }^{31}$ As called for by other researchers, there is a need for more sophisticated measures to support price increases and to reduce price gaps, and to understand and address TI strategies 
designed to undermine tax increases. Such measures may include adoption of a larger specific excise tax element, ${ }^{57}$ delivering larger and unannounced tax increases, and increasing taxation of RYO tobacco. ${ }^{5,8,31}$ Furthermore, non-tax pricing strategies, such as the adoption of minimum markup/price laws, an effective method of increasing prices of the cheapest cigarettes, should be considered and may serve to complement tax-based policies. ${ }^{58-60}$

The study has implications for tax design and implementation in other regions that are seeking to strengthen tobacco control and for those considering taxes on other products harmful to health, such as products of the alcohol and sugar-sweetened beverage industries, which have adopted similar strategies to that of the TI to maintain consumption and influence policy. ${ }^{61-63}$

\section{CONCLUSIONS}

This study extends previous research in the UK, providing evidence to suggest that the TI adopts pricing strategies that reduce the impact of tobacco tax increases in EU countries by maintaining the availability of cheaper forms of tobacco. Such activities serve to jeopardise public health gains and exacerbate smoking-related inequalities. We provide further evidence of the need for strengthening, and ongoing evaluation of, tobacco taxation policy and delivery, to achieve the public health objective of tobacco taxation. 


\section{WHAT THIS PAPER ADDS:}

\section{What is already known on this subject:}

$\diamond$ Comprehensive UK-based studies show that the Tobacco Industry (TI) adopts pricing strategies that undermine the public health impacts of tobacco taxes.

$\diamond$ Across the EU, there are large differences in prices of manufactured cigarettes and RYO tobacco products.

\section{What important gaps in knowledge exist on this topic:}

$\diamond$ Little is known about contemporary use of pricing strategies by the TI across the EU, even though this information is important to inform current revisions to tobacco tax legislation.

$\diamond \quad$ Analyses of price differentials in tobacco markets across the EU are lacking.

\section{What this paper adds:}

$\diamond \quad$ The pricing strategies adopted by the TI potentially undermine the impact of tobacco taxes across the EU by retaining cheaper forms of tobacco in the market.

$\diamond \quad$ The TI appears to absorb tax increases differentially between cigarette prices segments thereby maintaining cheaper manufactured cigarettes in the EU market.

$\diamond$ The current revision to the EU tobacco tax Directive offers scope for advancing public health objectives. 
Competing interests: None declared

Ethics: not required

Funding: JB is supported by personal fellowships from the Netherlands Lung Foundation and Erasmus MC. CM is funded through Research Professorship award NIHR RP_201404-032 from the National Institute for Health Research (NIHR). The Public Health Policy Evaluation Unit is grateful for support from the NIHR School of Public Health Research.

Role of the Funder: The funding sources had no role in the design and conduct of the study; collection, management, analysis, and interpretation of the data; preparation, review, or approval of the manuscript, or the decision to submit the manuscript for publication.

Contributions: MvS, FF and MM developed the initial research concept and design. MvS performed the analyses with the support of FF and MM. MvS drafted the original manuscript; FF, MM, CM and JB contributed to the manuscript preparation, interpretation and discussion of the findings.

Acknowledgments: We wish to thank Dr Kiara Chang for comments and advice on the revision of the supplementary methods. 


\section{REFERENCES}

1. Chaloupka FJ, Yurekli A, Fong GT. Tobacco taxes as a tobacco control strategy. Tob Control. 2012;21(2):172-180.

2. Chaloupka FJ, Straif K, Leon ME, Working Group IA for R on C. Effectiveness of tax and price policies in tobacco control. Tob Control. 2011;20(3):235-238.

3. IARC. Handbook of Cancer Prevention Volume 14 - Effectiveness of Tax and Price Policies for Tobacco Control. Lyon, France; 2011.

http://www.iarc.fr/en/publications/pdfs-online/prev/handbook14/index.php. Accessed August 7, 2018.

4. World Health Organization. WHO Framework Convention on Tobacco Control. Geneva: World Health Organization; 2003.

http://www.who.int/fctc/text_download/en/. Accessed August 9, 2018.

5. Hiscock R, Branston JR, McNeill A, Hitchman SC, Partos TR, Gilmore AB. Tobacco industry strategies undermine government tax policy: evidence from commercial data. Tob Control. 2018;27:488-497.

6. Gilmore AB, Tavakoly B, Taylor G, Reed H. Understanding tobacco industry pricing strategy and whether it undermines tobacco tax policy: the example of the UK cigarette market. Addiction. 2013;108(7):1317-1326.

7. Shirane R, Smith K, Ross H, Silver KE, Williams S, Gilmore A. Tobacco industry manipulation of tobacco excise and tobacco advertising policies in the Czech Republic: an analysis of tobacco industry documents. PLoS Med. 2012;9(6):e1001248.

8. Currie L, Townsend J, Roux ML, Godfrey F, Gallus S, Gilmore AB. Policy Recommendations for Tobacco Taxation in the European Union Integrated Research Findings from the PPACTE Project. Dublin; 2012.

http://www.tri.ie/uploads/3/1/3/6/31366051/ppacte_policy_recommendations_and_inte grated_report.pdf. Accessed August 9, 2018.

9. Nargis N, Fong GT, Chaloupka FJ, Li Q. The choice of discount brand cigarettes: a comparative analysis of International Tobacco Control surveys in Canada and the USA (2002-2005). Tob Control. 2014;23 Suppl 1(suppl 1):i86-96.

10. Linegar DJ, van Walbeek C. The effect of excise tax increases on cigarette prices in South Africa. Tob Control. 2018;27(1):65-71.

11. Marsh L, Cameron C, Quigg R, et al. The impact of an increase in excise tax on the retail price of tobacco in New Zealand. Tob Control. 2016;25(4):458-463.

12. Hanewinkel R, Isensee B. Five in a row - reactions of smokers to tobacco tax increases: population-based cross-sectional studies in Germany 2001-2006. Tob Control. 2007;16(1):34-37.

13. Brock B, Choi K, Boyle RG, Moilanen M, Schillo BA. Tobacco product prices before and after a statewide tobacco tax increase. Tob Control. 2016;25(2):166-173.

14. Gilmore AB, Tavakoly B, Hiscock R, Taylor G. Smoking patterns in Great Britain: the rise of cheap cigarette brands and roll your own (RYO) tobacco. J Public Health (Bangkok). 2015;37(1):78-88.

15. Brown AK, Nagelhout GE, van den Putte B, et al. Trends and socioeconomic differences in roll-your-own tobacco use: findings from the ITC Europe Surveys. Tob Control. 2015;24 Suppl 3(Suppl 3):iii11-iii16.

16. Partos TR, Gilmore AB, Hitchman SC, Hiscock R, Branston JR, McNeill A. Availability and Use of Cheap Tobacco in the United Kingdom 2002-2014: Findings From the International Tobacco Control Project. Nicotine Tob Res. 2018;20(6):714724.

17. Branston JR, McNeill A, Gilmore AB, Hiscock R, Partos TR. Keeping smoking 
affordable in higher tax environments via smoking thinner roll-your-own cigarettes: Findings from the International Tobacco Control Four Country Survey 2006-15. Drug Alcohol Depend. 2018;193:110-116.

18. Ross H, Blecher E, Yan L, Hyland A. Do cigarette prices motivate smokers to quit? New evidence from the ITC survey. Addiction. 2011;106(3):609-619.

19. Ross H, Blecher E, Yan L, Cummings KM. Predictors of What Smokers Say They Will Do in Response to Future Price Increases. Findings From the International Tobacco Control (ITC) Four Country Survey. Nicotine Tob Res. 2011;13(6):419-425.

20. Licht AS, Hyland AJ, O'Connor RJ, et al. How Do Price Minimizing Behaviors Impact Smoking Cessation? Findings from the International Tobacco Control (ITC) Four Country Survey. Int J Environ Res Public Health. 2011;8(5):1671-1691.

21. Hyland A, Higbee C, Li Q, et al. Access to low-taxed cigarettes deters smoking cessation attempts. Am J Public Health. 2005;95(6):994-995.

22. Howell $\mathrm{F}$. The Irish tobacco industry position on price increases on tobacco products. Tob Control. 2012;21(5):514-516.

23. The Council of the European Union. Council Directive 2010/12/EU of 16 February 2010 Amending Directives 92/79/EEC, 92/80/EEC and 95/59/EC on the Structure and Rates of Excise Duty Applied on Manufactured Tobacco and Directive 2008/118/EC.; 2010. https://eurlex.europa.eu/LexUriServ/LexUriServ.do?uri=OJ:L:2010:050:0001:0007:EN:PDF. Accessed October 5, 2018.

24. European Commission. Report from the Commission to the Council on Directive 2011/64/EU on the Structure and Rates of Excise Duty Applied to Manufactured Tobacco. Brussels; 2018. http://www.consilium.europa.eu/en/press/pressreleases/2016/03/08-ecofin-conclusions-structure-rates-. Accessed October 5, 2018.

25. Euromonitor International - Tobacco. https://www.portal.euromonitor.com/portal/magazine/index?PageTypeId=1\&MenuCo de $=$ TB \&PageId=38\&ImageUrl=\%2Ficons $\% 2$ FIndustries $\% 2$ Findustry-iconsTobacco.png\&Title=Tobacco. Accessed July 16, 2018.

26. European Commission. Communication and Information Resource Centre for Administrations, Businesses and Citizens; Excise Duties Tables (Archive) Library. https://circabc.europa.eu/faces/jsp/extension/wai/navigation/container.jsp. Accessed July 19, 2018.

27. Filippidis FT, Laverty AA, Hone T, Been J V., Millett C. Association of Cigarette Price Differentials With Infant Mortality in 23 European Union Countries. JAMA Pediatr. 2017;171(11):1100-1106.

28. Gallus S, Lugo A, Ghislandi S, La Vecchia C, Gilmore AB. Roll-your-own cigarettes in Europe: use, weight and implications for fiscal policies. Eur J Cancer Prev. 2014;23(3):186-192.

29. López-Nicolás Á, Cobacho MB, Fernández E. The Spanish tobacco tax loopholes and their consequences. Tob Control. 2013;22(e1):e21-24.

30. XE Corporation. Current and Historical Rate Tables. https://www.xe.com/currencytables/. Accessed June 17, 2018.

31. López-Nicolás Á, Stoklosa M. Tax harmonisation and tobacco product prices in the European Union, 2004-2015. Tob Control. published Online First: 17 August 2018 doi:10.1136/TOBACCOCONTROL-2018-054342

32. Eurostat. Measuring inflation - the Harmonised Index of Consumer Prices (HICP), European Central Bank, Eurosystem. https://www.ecb.europa.eu/stats/macroeconomic_and_sectoral/hicp/html/index.en.html . Accessed July 16, 2018. 
33. Tauras J, Peck R, Chaloupka F. The Role of Retail Prices and Promotions in Determining Cigarette Brand Market Shares. Rev Ind Organ. 2006;28:253-284.

34. Breton MO, Britton J, Huang Y, Bogdanovica I. Cigarette brand diversity and price changes during the implementation of plain packaging in the United Kingdom. Addiction. 2018;113(10):1883-1894.

35. Atuk O, Özmen MU. Firm strategy and consumer behaviour under a complex tobacco tax system: implications for the effectiveness of taxation on tobacco control. Tob Control. 2017;26(3):277-283.

36. Amato MS, Boyle RG, Brock B. Higher price, fewer packs: evaluating a tobacco tax increase with cigarette sales data. Am J Public Health. 2015;105(3):e5-8.

37. Shang C, Chaloupka FJ, Zahra N, Fong GT. The distribution of cigarette prices under different tax structures: findings from the International Tobacco Control Policy Evaluation (ITC) Project. Tob Control. 2014;23 Suppl 1(suppl 1):i23-9.

38. Blecher E, Ross H, Leon ME. Cigarette affordability in Europe. Tob Control. 2013;22(4):e6.

39. Wooldridge JM. Econometric Analysis of Cross Section and Panel Data. Cambridge, MA: MIT Press; 2010.

40. StataCorp LLC. Data Analysis and Statistical Software | Stata. https://www.stata.com/. Accessed August 17, 2018.

41. Ross H, Blecher E, Yan L, Hyland A. Do cigarette prices motivate smokers to quit? New evidence from the ITC survey. Addiction. 2011;106(3):609-619.

42. Stoklosa M, Goma F, Nargis N, et al. Price, tax and tobacco product substitution in Zambia. Tob Control. published Online First: 24 March 2018 doi:10.1136/tobaccocontrol-2017-054037.

43. Hanewinkel R, Radden C, Rosenkranz T. Price increase causes fewer sales of factorymade cigarettes and higher sales of cheaper loose tobacco in Germany. Health Econ. 2008;17(6):683-693.

44. Mindell J, Whynes DK. Cigarette consumption in The Netherlands 1970-1995: does tax policy encourage the use of hand-rolling tobacco? Eur J Public Health. 2000;10(3):214-219.

45. Curti D, Shang C, Ridgeway W, Chaloupka FJ, Fong GT. The use of legal, illegal and roll-your-own cigarettes to increasing tobacco excise taxes and comprehensive tobacco control policies: findings from the ITC Uruguay Survey. Tob Control. 2015;24 Suppl 3:iii17-iii24.

46. Skafida V, Silver KE, Rechel BPD, Gilmore AB. Change in tobacco excise policy in Bulgaria: the role of tobacco industry lobbying and smuggling. Tob Control. 2014;23(e1):e75-84.

47. Gilmore $\mathrm{AB}, \mathrm{McKee} \mathrm{M}$. Tobacco and transition: an overview of industry investments, impact and influence in the former Soviet Union. Tob Control. 2004;13(2):136-142.

48. Rothwell L, Britton J, Bogdanovica I. The relation between cigarette price and handrolling tobacco consumption in the UK: an ecological study. BMJ Open. 2015;5(6):e007697.

49. Delipalla S, O'Donnell O. Estimating tax incidence, market power and market conduct: The European cigarette industry. Int J Ind Organ. 2001;19(6):885-908.

50. Ross H, Stoklosa M, Krasovsky K. Economic and public health impact of 2007-2010 tobacco tax increases in Ukraine. Tob Control. 2012;21(4):429-435.

51. Euromonitor International. Cigarettes in Western Europe.; 2018. https://www.portal.euromonitor.com/portal/analysis/tab. Accessed August 14, 2018.

52. Estelami H, Lehmann DR. The Impact of Research Design on Consumer Price Recall Accuracy: An Integrative Review. J Acad Mark Sci. 2001;29(1):36-49. 
53. Schindler RM, Wiman AR. Effects of odd pricing on price recall. J Bus Res. 1989;19(3):165-177.

54. Hawkes C. Dietary Implications of Supermarket Development: A Global Perspective. Dev Policy Rev. 2008;26(6):657-692.

55. $\mathrm{Ng} \mathrm{M,} \mathrm{Freeman} \mathrm{MK,} \mathrm{Fleming} \mathrm{TD,} \mathrm{et} \mathrm{al.} \mathrm{Smoking} \mathrm{Prevalence} \mathrm{and} \mathrm{Cigarette}$ Consumption in 187 Countries, 1980-2012. JAMA. 2014;311(2):183-192.

56. Gilmore AB, Gallagher AWA, Rowell A. Tobacco industry's elaborate attempts to control a global track and trace system and fundamentally undermine the Illicit Trade Protocol. Tob Control. published Online First; 13 June 2018 doi:doi:10.1136/.

57. Shang C, Lee HM, Chaloupka FJ, Fong GT, Thompson M, O'Connor RJ. Association between tax structure and cigarette consumption: findings from the International Tobacco Control Policy Evaluation (ITC) Project. Tob Control. published Onlien First; 1 May 2018 doi:10.1136/tobaccocontrol-2017-054160.

58. Huang J, Chriqui JF, DeLong H, Mirza M, Diaz MC, Chaloupka FJ. Do state minimum markup/price laws work? Evidence from retail scanner data and TUS-CPS. Tob Control. 2016;25(Suppl 1):i52-i59. http://www.ncbi.nlm.nih.gov/pubmed/27697948. Accessed August 19, 2018.

59. Liber AC, Ross H, Omar M, Chaloupka FJ. The impact of the Malaysian minimum cigarette price law: findings from the ITC Malaysia Survey. Tob Control. 2015;24 Suppl 3(Suppl 3):iii83-iii87.

60. Gigliotti A, Figueiredo VC, Madruga CS, et al. How smokers may react to cigarette taxes and price increases in Brazil: data from a national survey. BMC Public Health. $2014 ; 14: 327$.

61. George A. Not so sweet refrain: sugar-sweetened beverage taxes, industry opposition and harnessing the lessons learned from tobacco control legal challenges. Heal Econ Policy Law. May 2018:1-27.

62. Martino FP, Miller PG, Coomber K, Hancock L, Kypri K. Analysis of Alcohol Industry Submissions against Marketing Regulation. Vrana KE, ed. PLoS One. 2017;12(1):e0170366.

63. Tselengidis A, Östergren P-O. Lobbying against sugar taxation in the European Union: Analysing the lobbying arguments and tactics of stakeholders in the food and drink industries. Scand J Public Health. published Online First: 1 July 2018 doi: $10.1177 / 1403494818787102$. 
Figure 1: Adjusted median 20-stick pack price for manufactured and RYO cigarettes from 2006 to 2017 in countries who (A) joined the EU prior to 2004 (B) countries who joined the EU after 2004.

* Note the use of different scales for Ireland and the United Kingdom.

Note: Prices were adjusted for inflation using the HICP and pack sizes were standardised to 20 sticks. Non-Euro prices have been converted to Euros using historical exchange rates. Pricing data was not available for every year in all countries (see methods for details).

Figure 2: Adjusted median net revenue for manufactured and RYO cigarettes from 2006 to 2017 in countries who (A) joined the EU prior to 2004 and (B) joined the EU post 2004.

* Note, different scales used for Ireland and the United Kingdom.

Note: Revenue was adjusted for inflation using the HICP. All results are shown in Euros. Pricing data was not available for every year in all countries (see methods for details). 


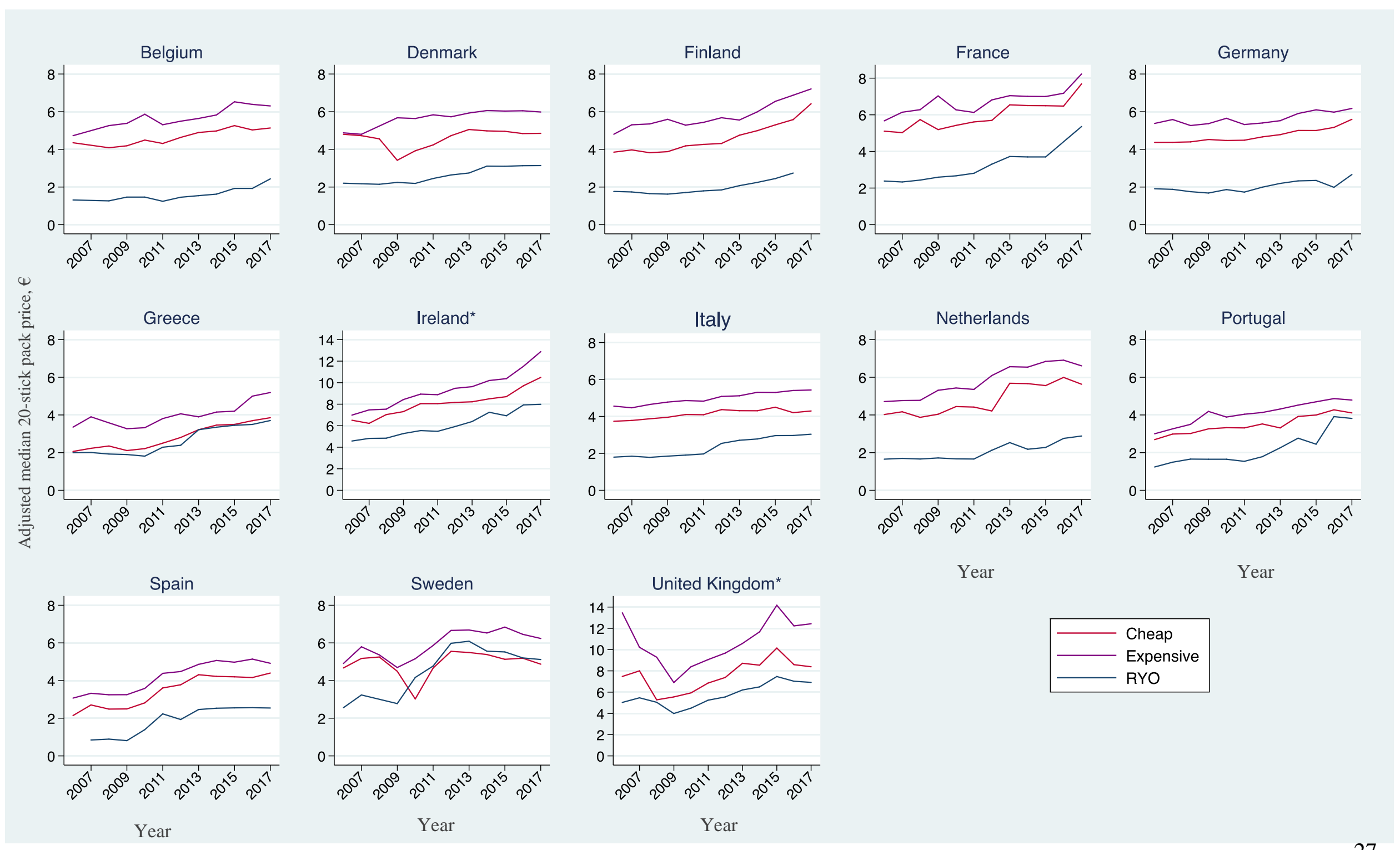




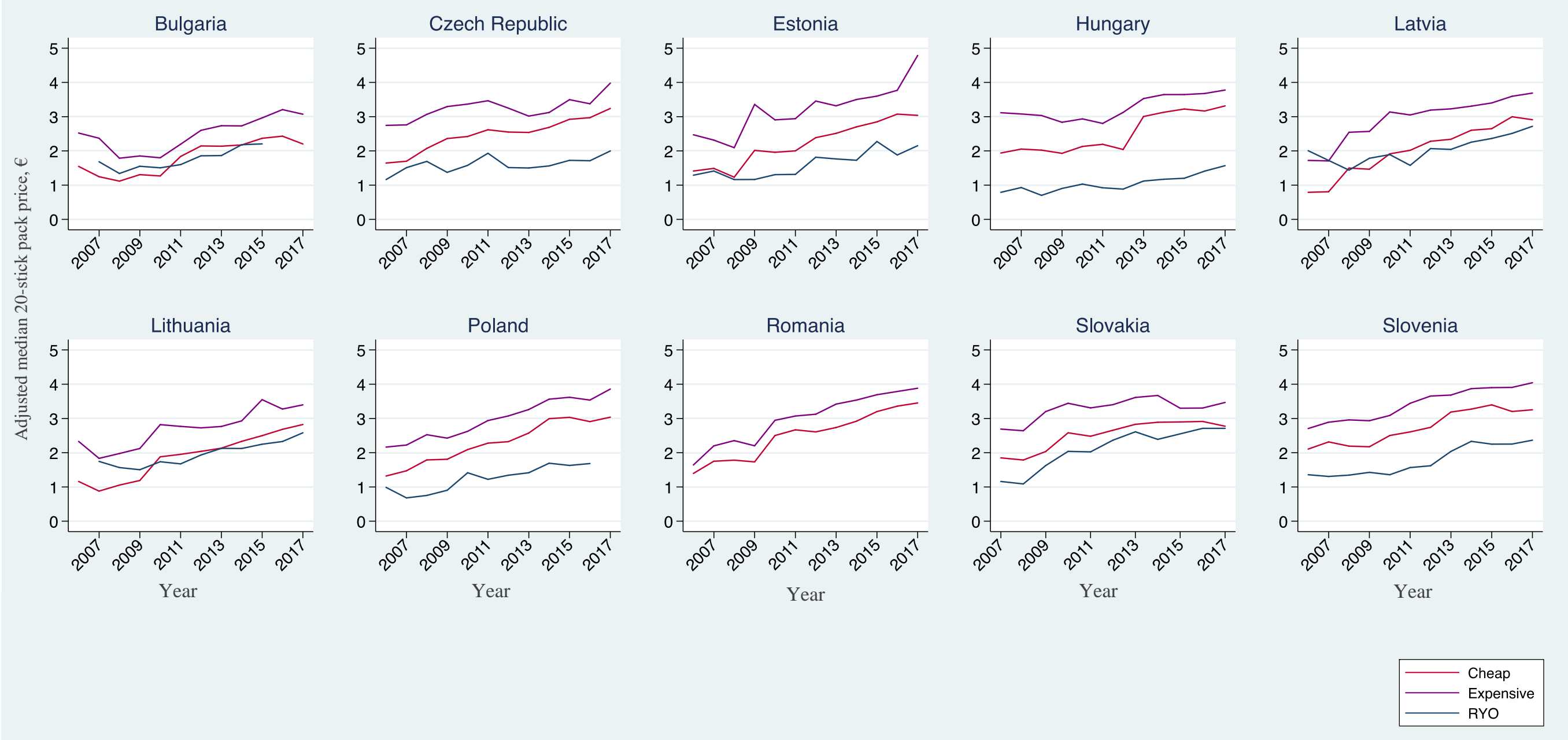


A

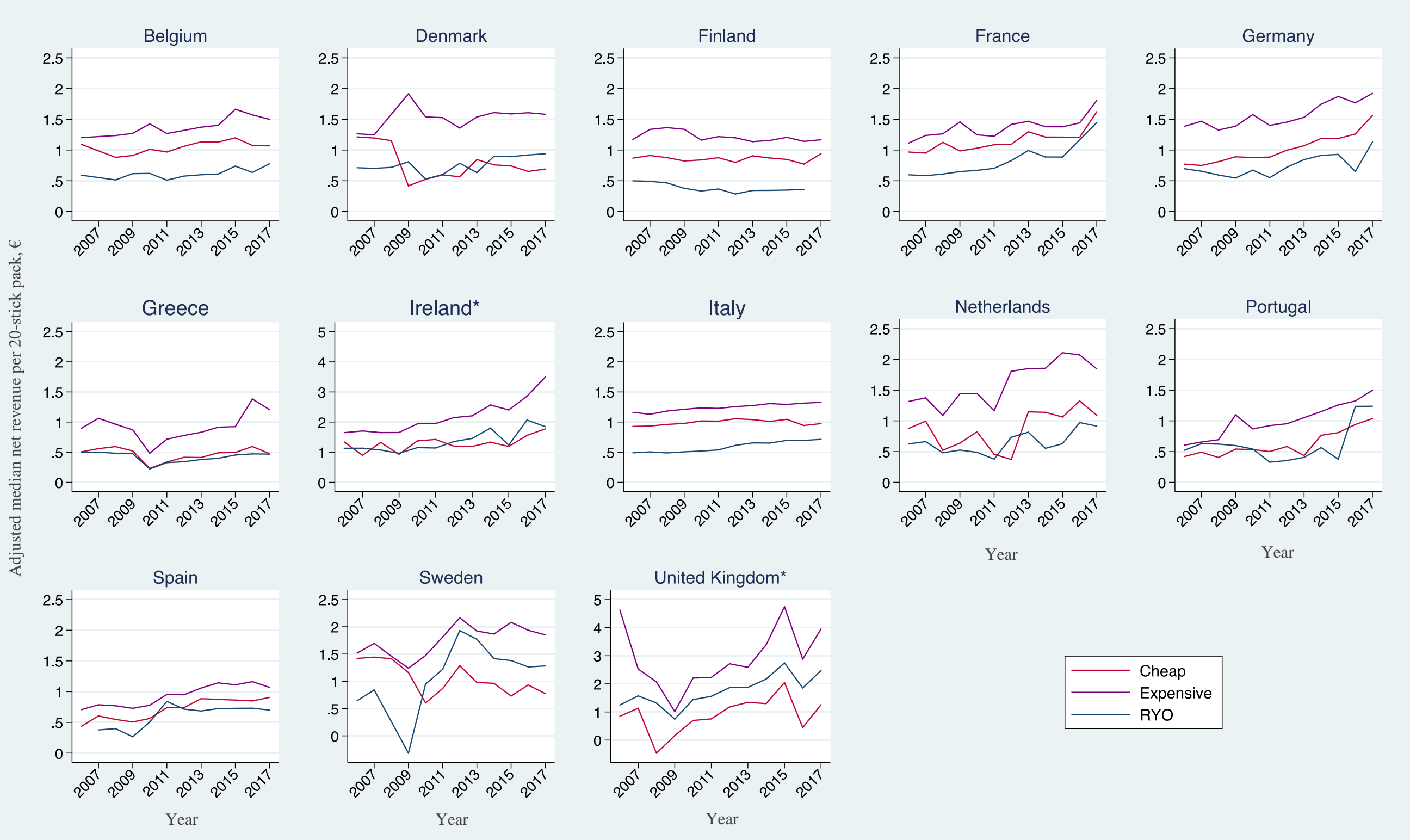



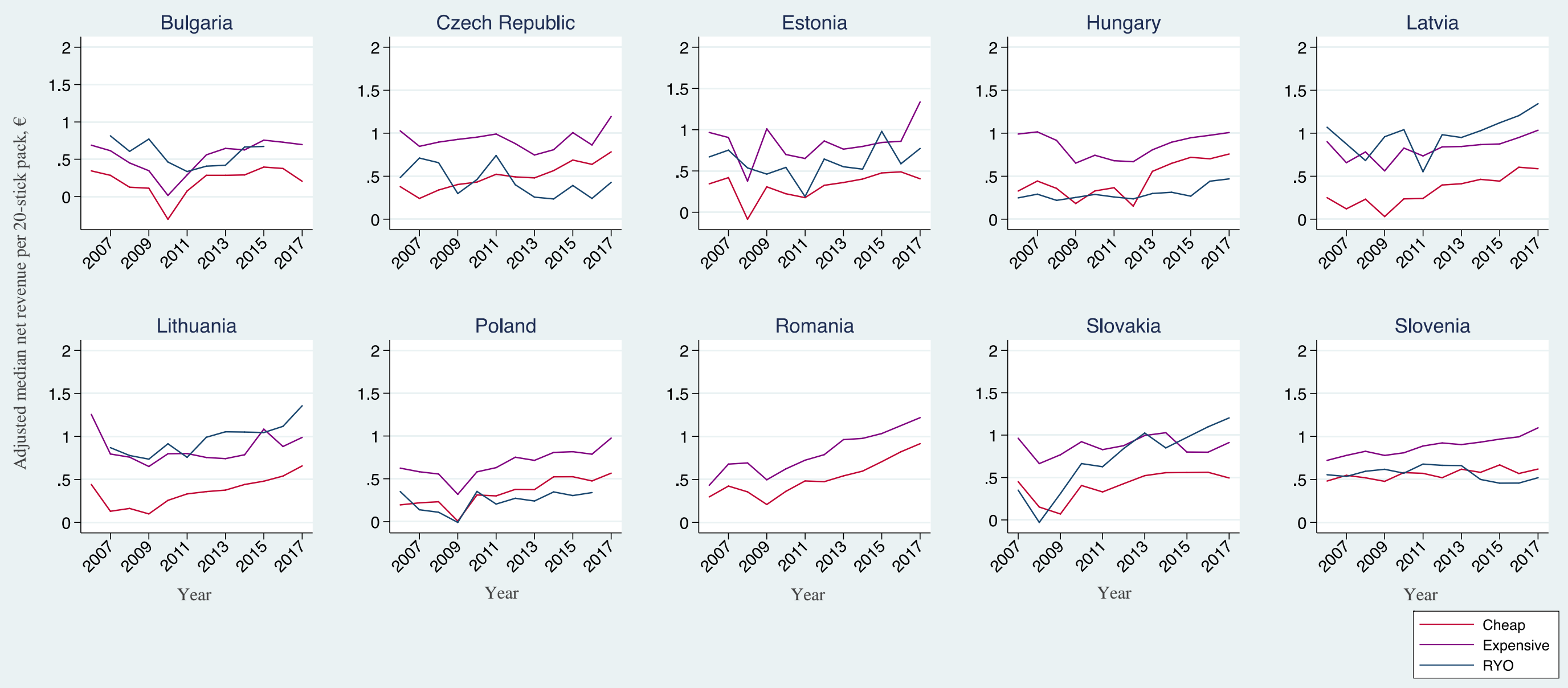
